\title{
Phentolamine Mesylate
}

National Cancer Institute

\section{Source}

National Cancer Institute. Phentolamine Mesylate. NCI Thesaurus. Code C38691.

The mesylate salt of a synthetic imidazoline with alpha-adrenergic antagonist activity. As a competitive alpha-adrenergic antagonist, phentolamine binds to alpha-1 and alpha-2 receptors, resulting in a decrease in peripheral vascular resistance and vasodilatation. This agent also may block 5-hydroxytryptamine (5-HT) receptors and stimulate release of histamine from mast cells. 